引用格式: 李升发, 李秀彬, 辛良杰, 等. 中国山区耕地撂荒程度及空间分布一一基于全国山区抽样调查结果 $[\mathrm{J}]$. 资源科学, 2017, 39 (10) : 1801-1811. [Li S F, Li X B , Xin L J et al. Extent and distribution of cropland abandonment in Chinese mountainous areas[J]. Resources Science, 2017, 39(10): 1801-1811.] DOI: 10.18402/resci.2017.10.01

\title{
中国山区耕地撂荒程度及空间分布 基于全国山区抽样调查结果
}

\section{李升发 ${ }^{1,2,3}$, 李秀涁 ${ }^{1,2}$, 辛良杰 ${ }^{1}$, 谈明洪 ${ }^{1}$, 王 学 ${ }^{1}$, 王仁靖 ${ }^{1,2}$, 蒋 敏 $^{1,2}$, 王亚辉 ${ }^{1,2}$}

(1. 中国科学院地理科学与资源研究所陆地表层格局与模拟院重点实验室, 北京 100101 ;

2. 中国科学院大学, 北京 $100049 ; 3$.广州地理研究所,广州 510070)

\begin{abstract}
摘 要: 耕地摆荒是当前全球山区主要的土地利用变化现象,它深刻地改变了山区农村土地利用结构、农业景 观和农户生计,并带来了巨大的生态环境和社会经济效应。2000年以来,随着中国劳动力成本的快速上升和农村 劳动力的大量析出, 中国山区农业因地形限制, 机械化发展受阻,耕地面临着较大的蕒荒风险。越来越多的案例研 究和报道表明中国山区耕地眇荒现象越演越烈。中国山区面积广、坡耕地比重大,耕地蕒荒不仅关系到山区农地 的合理利用政策和山区可持续发展政策的制定, 并可能引起粮食安全问题, 但目前仍缺少全国层面的定量化评估 研究。因此, 本研究通过开展大范围的抽样调查对中国山区县摆荒规模进行了推算, 以期为相关政策制定以及耕 地边际化进一步研究提供参考。研究结果表明,在 235 个调查村庄中, $78.3 \%$ 的村庄出现耕地撂荒现象; 基于县样本 统计的 2014-2015 年全国山区县耕地摆荒率为 $14.32 \%$; 山区耕地撂荒率在省级尺度上呈现出南高北低的空间格局, 其中, 长江流域一带的山区耕地撂荒率最高, 东北的长白山区最低。
\end{abstract}

关键词: 耕地撂荒; 耕地利用边际化; 习惯亩; 中国山区

DOI: $10.18402 /$ resci.2017.10.01

\section{1 引言}

改革开放以来, 随着工业化的快速发展, 中国 城镇化进程快速推进, 尤其是 1996 年以来, 全国城 镇化率以平均每年约 $1.4 \%$ 的增幅增长, 乡村人口数 量也从原来的净增加阶段进人到净减少阶段。伴 随城镇化和工业化水平的提高, 务工机会大量增 加, 务工工资快速增长 ${ }^{[1,2]}$, 促使越来越多的农村劳 动力向城镇地区和非农产业部门转移 ${ }^{[3]}$ 。农民工人 口的不断增长和农业劳动力数量的持续减少已成 为 2003 年以来中国劳动力变化的显著特征。20022013 年期间, 全国平均每年减少农业劳动力 1133 万 人。尽管中央政府在过去十多年一直强调发展 “三 农”, 但城乡收人的绝对差距仍然在不断扩大, 随着 新型城镇化战略的实施, 可以预见未来较长一段时
间, 中国城镇化进程仍将以较快的速度推进,农业 劳动力数量也将继续减少。有学者预计, 到 2030 年 中国的农业劳动力数量将不足 2010 年的一半 ${ }^{[4]}$ 。不 仅如此, 随着农业劳动力数量的不断减少, 农业劳 动力年龄结构的老化程度也在加剧。据统计, 2010 年中国农业劳动力平均年龄已超过 45 岁, 表明了中 国已进人农业劳动力老龄化时代 ${ }^{[5]}$, 并且高龄化特 征极其明显 ${ }^{[6]}$ 。

为应对农业剩余劳动力的实质性减少和劳动 力价格上升, 2003 年以来, 中国农业生产方式向农 业机械化方向快速发展 ${ }^{[7,8]}$, 从而避免了耕地利用边 际化。然而, 在山地丘陵区, 崎岖的地形条件限制 了农业机械的投人,随着农业劳动力的析出以及老 龄化, 以坡耕地为代表的劣质耕地不断被边际化, 并

收稿日期: 2017-08-12; 修订日期: 2017-09-11

基金项目: 国家重点基础研究发展计划“973”项目(2015CB452706);国家自然科学基金重大国际合作项目(41161140352)。

作者简介: 李升发,男,广东三水人,博士,助理研究员,主要从事土地利用变化研究和土地规划相关工作。E-mail: 1i_shengfa@126.com 通讯作者:李秀涁,E-mail : lixb@igsnrr.ac.cn 
最终被撂荒[9]。发达国家的经验表明,农地撂荒是城 镇化和工业化过程中的普遍现象 ${ }^{[10-12]}$, 直至目前, 欧 洲地区的农地撂荒趋势仍在持续 ${ }^{[13]}$ 。2000年以来， 重庆、宁夏、湖北、江西等地的山区耕地撂荒现象也越 来越明显 ${ }^{[14-16]}$,耕地撂荒分布的地区非常广, 涉及 21 个省份 ${ }^{\left[{ }^{[1]}\right.}$,主要集中在山地丘陵地区。西南财经大 学中国家庭金融调查与研究中心对全国 29 个省、 262 个县市的住户跟踪调查发现, 2011 年和 2013 年 分别有 $13.5 \%$ 和 $15 \%$ 的农用地处于闲置状态 ${ }^{[18]}$ 。随 着中国工业化和城镇化进程的深人推进,农村劳动 力进一步析出以及留守农业劳动力的快速老龄化, 以坡耕地为代表的农业劳动密集型利用方式,被边 际化的可能性越来越高, 很可能加剧目前耕地撂荒 的范围和程度 ${ }^{[9,16]}$ 。

中国山地丘陵和高原面积广阔,占全国土地面 积比重超过了 $2 / 3$, 坡耕地比重也很大。第二次全 国土地调查结果显示, 中国 $6^{\circ}$ 以上的坡耕地面积占 全国耕地总量的 $27 \%$ 。坡耕地不利于机械化,在快 速城镇化和工业化发展过程中被边际化和撂荒的 可能性很高。假若山区耕地利用边际化继续发展， 山区耕地撂荒规模不断增加,这可能对中国山区农 村乃至全国的社会经济和生态环境产生深远影 响。目前中国山区的耕地撂荒规模仍缺少全国层 面的评估和测算,因此难以对山区耕地撂荒发展态 势作出有效的政策响应。为此,本研究采用抽样调 查方法推算全国及各省山区耕地撂荒程度,以期为 国家相关部门制定政策提供参考。需要说明的是, 本文的研究对象是完全停止耕种的土地,季节性撂 荒耕地、隐性撂荒耕地以及休耕地均不在本文调查 范围内。

\section{2 研究区及数据来源}

\section{1 研究区范围的选取}

根据已有研究, 山区耕地由于受到自然条件限 制, 在社会经济要素变化的驱动下, 首先会被边际 化和撂荒,因此本文将研究范围确定为中国山区。 目前关于山区的定义学术界仍没有统一的标准。 山区主要跟地形相关, 根据世界保护监测中心 (UNEP-WCMC), 符合以下几个条件即可划为山 地: (1)海拔大于 $2500 \mathrm{~m}$; (2)海拔在 1500 2500m 之 间且坡度大于 $2^{\circ}$; 3 海拔在 1000 1500m 之间且坡
度大于 $5^{\circ}$ 或局部高差大于 $300 \mathrm{~m}$; (4)海拔在 $300 ~$ $1000 \mathrm{~m}$ 之间且局部高差大于 $300 \mathrm{~m}^{[19]}$ 。然而, 山区并 不完全等同于山地,山区在空间分布上是连续和完 整,因此不能完全按照地形条件来定义,还应当加 上人口、土地利用和道路等经济社会要素 ${ }^{[20]}$ 。鉴于 中国大部分的社会经济数据是以县域为单元进行 统计, 因此以山区县为研究单元是较为合理的 选择。

关于山区县的定义, 本文采用《中国县域经济 统计年鉴》 ${ }^{[21]}$ 中的标准, 即县域内的山地面积大于 $80 \%$ 的县, 2011 年我国山区县(区)有 905 个(图 1), 约占全国土地总面积的 $45 \%$, 山区县的耕地面积约 占全国耕地总量的 $1 / 4$ 。从空间分布来看, 中国山 区县涵盖了 28 个省份 (不含港澳台), 土地总面积 432 万 $\mathrm{km}^{2}$, 在空间上主要分布在青藏高原、西南和 东南地区,上海、天津和江苏没有山区县。

\section{2 数据来源}

本文所使用的耕地撂荒数据均来自于作者在 2015-2016年开展的全国山区耕地撂荒抽样调查, 该调查的具体过程如下。

(1)抽样方法的确定。由于中国山区县的数量 及山区耕地资源空间分布极不均衡,简单随机抽样 方法获取的结果误差较大,而空间分层抽样方法因 考虑了空间自相关,抽样精度相对较高, 但该方法 的调查难度大、成本高,因此,本研究采用了分层抽 样与随机抽样结合的方法对中国 905 个山区县进行 抽样调查。调查抽样点布设的思路如下: 首先计算 各省拥有的山区县数量占比和耕地面积占比的平 均数, 以此作为每个省山区县数量的抽取比例; 之 后在每个省内采取随机抽样方法抽取相应数量的 样本县; 最后在每个样本县内采取随机抽样方法对 村庄和农户进行调查。考虑到中国山区范围广的 特点以及随机抽样方法的要求, 为尽量提高抽样调 查结果的可靠性, 本次抽样调查将抽样比例确定为 $15 \%$ 左右, 约 135 个县。参考同类调查的经验, 为防 止调查员对数据造假, 不宜给单个调查员安排过多 的调查任务量, 同时也为了保证不同地区间的样本 量的相对平衡, 最终确定每个县调查 1 2个行政村, 每个行政村调查 10 15 个农户,调查样本量(户)控 制在 3990 份以内。 


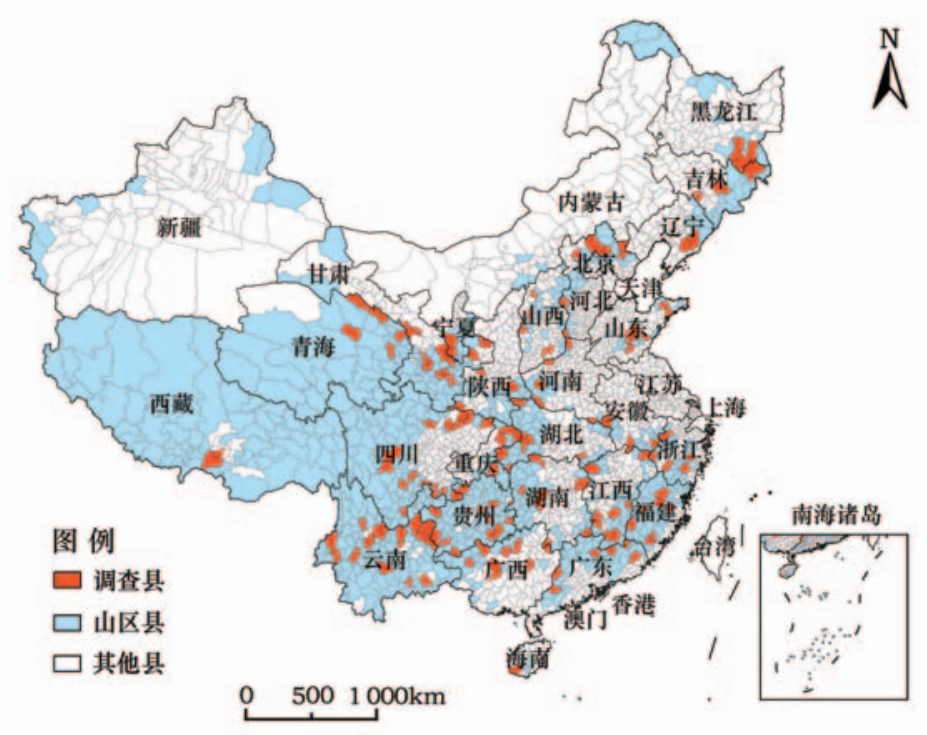

图 1 中国山区县及调查县空间分布

Figure 1 Distribution of mountainous counties and surveyed counties in China 注: 由于数据获取困难, 本次研究不包括香港、台湾和澳门。

(2) 调查方法的确定。由于本次调查涉及的范 围广且相对分散,并且调查范围限定在中国山区的 农村地区,而常规的实地调查手段需要大量的人员 和资金投人,对于这种大范围且调查人员、时间十 分有限的情况下完成的农户调查, 通过调查县所在 地的农村大学生在假期返乡时候开展调查和观察 来完成是比较快速而有效的方法。谢晨等曾通过 大学生假期返乡进行人户调查完成全国关于退耕 还林政策的农户调查, 由此对中国退耕还林政策做 了系统的总结 ${ }^{[22]}$ 。宋伟利用中国农业大学的本科生 在暑期完成了 15 个省份的农村宅基地现状调查 ${ }^{[23]}$ 。 因此,本研究借鉴该种方法开展本次调查。

(3)调查人员的篎选及培训。为更迅速地找到 合适的调查人, 本次调查主要通过高校人际网络 (QQ群、校内网等)发布广告的方式寻找符合条件 的调查人。在调查人员选择原则上,调查人必须是 家 (或有亲戚)在本研究确定的山区县名单内的农 村地区,并且能够利用假期在自己家庭所在村庄和 附近村庄进行调查。为了提高调查表的完成度和 准确性, 优先选择地理科学、土地资源、资源科学等 与调查内容较为相关专业的大学生或研究生, 同时 考虑调查人员家庭所在地, 尽量保证各省份的调查 样本点在空间上相对均衡地分布, 而不是集中在某 个地区。大学生假期返乡调查共开展了四轮, 分别
是在 2015 年和 2016 年的寒暑假,共联系到来自 50 多个高校符合条件的调查员超过200名。

在确定调查人员名单之后, 我们给每位调查人 员通过网络发送调查表及其他调查材料(调查项解 释、调查开展过程讲义和介绍信等)。为保障调查 人员对调查主要内容和重点概念熟悉, 还通过在线 方式对调查重点内容和注意事项进行讲解,并在调 查期间与各位调查人保持密切联系, 及时解决其在 调查过程中所碰到的问题，以保证调查表的质量。

(4)实地补充调查开展。由于部分地区无法找 到足够数量的合格调查员, 需要通过对样本缺漏的 省份进行补充调查以完成计划所需的全部样本数 量。补充调查和实地考察主要开展了四次, 分别为 2015 年 10 月到 11 月的江西-湖北-福建调查、2016 年7月的浙江-安徽-江西调查,2016年9月上旬的黑 龙江-吉林调查以及 2016 年 9 月中下旬的广西-湖 南-江西调查。实地补充调查主要是针对样本量不 足的省份, 调查的内容和要求与大学生假期返乡调 查的完全一致。

(5)调查表回收。大学生假期返乡调查共发放 村调查表 304 份, 农户表 4560 份, 共回收有效村调 查表 201 份,农户调查表 2415 份。通过实地调查共 获得有效的村调查表 64 份, 有效农户调查表 791 份。综合两种调查方法共获得有效的村调查表 265 
份, 有效回收率 $72 \%$, 有效的农户调查表 3206 份, 有 效回收率 $60 \%$ 。调查范围涉及 25 个省份、 153 个县, 由于内蒙古、新疆、北京没有找到合适的调查员所 以没有进行调查, 但这三个省份山区县数量很小, 合共 15 个, 仅占山区县总数的 $1.6 \%$,所以对总体抽 样调查结果的影响很小。

(6)调查表质量核查。在调查员完成调查后, 对电子版和纸质调查表都进行了回收, 以便对录人 数据进行检查。本研究制定了一套有效的逻辑标 准对每一份调查表的调查内容的真实性和准确性 进行核对,在发现问题数据后与调查员取得联系, 要求调查员对疑问数据进行补充调查和校正, 并要 求其对部分可能失真或空缺数据进行电话回访, 尽 可能提高调查数据的真实性和有效性。另外,抽取 了部分质量较差的调查表的调查对象(农户和村干 部)进行电话回访,未发现有作弊现象。

(7) 调查样本耖选。由于部分省份回收的调查 样本量过多,不符合分层抽样的要求,因此,根据调 查点的空间分布情况以及调查质量, 删除了部分质 量较差的和扎堆的样本, 最终使用到的村样本总数 为 235 个,农户调查样本总数为 2994 个, 调查范围 涉及 142 个县, 占山区县总数的 $15.7 \%$, 总体上达到 了调查方案设计的目标。本次调查时间跨度两年, 其中 2015 年完成调查的村调查表 109 份, 比重为 $46 \%, 2016$ 年完成调查的村调查表 126 份, 比重为 $54 \%$,农户表的年份构成与村表基本相同。所有调 查内容均针对上一年的农村和农户家庭数值, 亦即 2014 年和 2015 年。

\section{3 研究方法}

\section{1 抽样调查数据修正}

\subsection{1 习惯亩转标准亩}

由于山区耕地质量和地形条件差异很大,不同 地方根据当地的自然条件、测量习惯形成了各自的 测量单位。它考虑了土壤质量、地形和耕作时间投 人,如在南方地区常用担、挑或石等重量单位作为 面积量算单位,而一些地形崎岖的地方则采用劳动 投人当量作为面积量算单位 ${ }^{[24,25]}$ 。由于各地的自然 条件和种植习惯不一, 因此不同地方的习惯亩与标 准亩之间的折算系数也不一样。通常平坦的耕地 比坡耕地质量更好、单产更高,而坡耕地需要投人
比 1 亩更多的土地才能得到与 1 亩平地相同的产 量, 亦即 1 习惯亩 $>1$ 标准亩, 习惯亩也称为大亩。 习惯亩系数一般在 1 2 之间,一般来说地形陡峭崎 岖,习惯亩系数越大 ${ }^{[26]}$, 个别地区的习惯亩系数甚至 可以达到 4 以上 ${ }^{[27]}$ 。此外, 山区地形崎岖,加上丈量 方式简郖、丈量标准不严,所以部分地方测量存在 很大的误差,导致承包面积明显大于实测面积。

在实行家庭联产承包责任制时,大部分山区并 没有对耕地进行重新量算, 而是直接沿用了原来的 大亩量算单位和量算结果,这一方面能够将不同质 量/单产的集体土地相对公平的发包给农户，而另一 方面,对于基层政府部门而言,使用习惯亩作为承 包面积、计税计费面积不仅能够少交农业税，而且 还能提高名义上的单产, 因此他们也默许村干部和 农户使用习惯亩作为量算单位。对于中央政府而 言, 为了确保农村政策的稳定性和连续性,各地的 计量单位就一直沿用至今 ${ }^{[28]}$ 。

本研究使用的各村习惯亩系数主要根据村干 部和农户的认知进行确定, 部分村庄是通过调查员 以及实地调查过程中对若干个地块的面积进行测 量,然后通过比较测量面积与承包面积计算出习惯 亩转换系数。此外, 个别村完成了农村土地确权, 通过比较承包面积和确权面积也可得出习惯亩系 数。然而, 相当一部分的村干部和农户不清楚是否 使用习惯亩以及习惯亩系数是多少, 只能通过间接 的方法进行推算。由于习惯亩面积一般是大于标 准亩的,所以使用习惯亩的村庄的粮食平均单产也 高于标准亩, 因此,通过粮食单产比较也能大致推 算标准亩的系数。推算的具体步骤如下：

(1)确定各地区主要粮食作物 (1 2 种)。

(2)由于统计年鉴上单产统计口径与农户调查 的口径不同,存在偏小的情况, 所以为了不高估习 惯亩系数,本研究以发改委价格司《全国农产品成 本收益资料汇编》的单产数值作为标准单产, 并以 近三年的单产平均值作为替代, 以减少气候波动的 影响,该单产数值为省级平均单产。

(3)计算统计年鉴上各调查县平均单产与统计 年鉴上该县所在省的平均单产的比值,将该比值乘 以步骤 (2)得到的平均单产从而得到各调查县实际 的单产。部分调查县没有数据则以县所属的地市 
单产为替代。

(4)利用农户调查数据计算各调查村的单产水 平, 并除以步骤 (3) 的实际单产得出最终的习惯亩 系数。

具体的公式如下:

$$
M_{\text {village }}=\frac{Y_{\text {village }} \times Y_{\text {province }}}{Y_{\text {agriculture }} \times Y_{\text {county }}}
$$

式中 $M_{\text {village }}$ 为某调查村的习惯亩折算系数; $Y_{\text {village }}$ 为 某调查村的平均粮食亩产; $Y_{\text {agriculture }}$ 为《全国农产品 成本收益资料汇编》某调查村所在省的近三年的粮 食平均单产; $Y_{\text {county }}$ 为某调查村所在县市的统计年 鉴上近三年对应的粮食作物平均单产; $Y_{\text {province }}$ 为某 调查村所在省的统计年鉴上近三年对应的粮食作 物平均单产。

\subsection{2 村表调查误差修正}

通常村干部了解信息比村民以及调查员多,因 此本研究关于耕地撂荒调查数据以村表调查结果 为主要依据。然而,在村表调查开展过程中发现, 部分村干部为避免担责存在瞒报耕地撂荒的情 况。为了减少村干部瞒报或少报的对结果造成的 误差。本研究根据农户调查土地调查表和农户撂 荒调查感知表对村撂荒数据进行一定的修正。修 正过程如下:

(1)瞒报村识别。瞒报村的识别主要是根据农 户土地调查表、农户撂荒调查感知表进行确定。若 农户土地调查表中耕地撂荒比例大于 $5 \%$ 或超过 50\%的农户认为村存在耕地撂荒现象, 而村表调查 中撂荒率为 0 或撂荒面积小于农户土地调查表中汇 总的撂荒面积,这时候可以基本判断为瞒报村。为 减少过度修正,本研究也结合调查员视角进一步核 实。最终确定为瞒报村的数量为 23 个。

（2)误差修正方法。修正的方法同样参考农户 土地调查表、农户撂荒调查感知表结果。若农户土 地调查表中的撂荒比例与农户撂荒调查感知表中 的撂荒比例 (平均值)之差在 $10 \%$ 以内, 以土地调查 表的数值为准。若差值在 $10 \%$ 以上, 根据调查员视 角进一步确定使用哪一个数值, 若调查员无法判断
则采用这两者的平均值。

另外,个别村庄村表调查的撂荒比重与农户土 地调查及撂荒感知调查结果有很大出人的情况, 根 据调查者反馈信息, 其主要原因是因为农户所关注 的是其所在的自然村大体情况,与村干部了解的整 个村的情况会存在较大的不一致,因此,本研究对 这种差异并没有修正。

\section{2 撂荒率计算}

\subsection{1 基于农户/村庄样本的撂荒率}

由于中国山区有多种土地边际化类型,在计算 撂荒率时,基期面积的不同会导致撂荒率计算有很 大的差异,因此需要在计算时进行明确。

撂荒率 I 是以基期全部耕地作为分母,其计算 公式如下:

$$
R_{i}=A a /(A c+A a+A g+A m) \times 100 \%
$$

式中 $R_{i}$ 为耕地撂荒率 $\mathrm{I} ; A a 、 A c 、 A g 、 A m$ 分别为 撂荒的耕地面积、正在种植的耕地面积、退耕还林 还草面积、改种果树/林木的耕地面积 ${ }^{1)}$ (下同)。

撂荒率 II 是以扣除期末发生退耕还林还草面 积后的基期耕地作为分母,其计算公式如下：

$$
R_{i i}=A a /(A c+A a+A m) \times 100 \%
$$

撂荒率 III 是以扣除期末发生退耕还林还草和 改种果树/林木的耕地面积后的基期耕地面积作为 分母,其计算公式如下:

$$
R_{i i i}=A a /(A c+A a) \times 100 \%
$$

\subsection{2 基于县样本的撂荒率}

由于部分县在调查过程中仅完成了一个村的 调查, 考虑到分层抽样的要求, 需要先把有两个或 以上调查村的县进行面积加权平均, 然后将全部县 的平均值进行面积加权平均, 最终得到全国山区县 的耕地撂荒率。以撂荒率 I 为例, 其计算公式 如下:

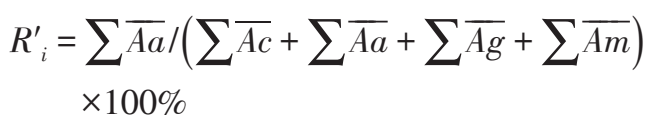

式中 $R_{i}^{\prime}$ 为基于县抽样调查的全国山区县撂荒率 $\mathrm{I} ; \overline{A a} 、 \overline{A c} 、 \overline{A g} 、 \overline{A m}$ 分别为各县平均的撂荒耕地 面积、正在经营的耕地面积、退耕还林面积、改种果

1)改种果树/林木是指原来种植农作物(粮食或经济作物)的耕地,但后来被农户改种为苹果、核桃、柑橘、毛竹、桉树等果树或林木,它与 退耕还林还草的区别在于,它是农户自发的行为,农户改种树之后一般不会获得补贴。 
树/林木的耕地面积的平均值。

采用同样的方法可计算出基于县样本的撂荒 率 II 、III。

\section{4 结果及分析}

\section{1 耕地撂荒出现范围和起始时间}

根据村表调查结果,截止到 2014-2015 年发生 耕地撂荒的村庄数量为 184 个, 占调查村庄总数的 $78.3 \%$,除黑龙江外,在其余调查的 24 个省份均有分 布。其中,重庆、浙江、江西、甘肃、安徽所调查的全 部村庄均有耕地撂荒现象。四川、福建、湖北、贵州 和广东的撂荒发生频率也在 $90 \%$ 左右(图 2)。东北
和华北地区是耕地撂荒发现频率最低的地区。

从撂荒起始时间来看,耕地撂荒最早是从 1990 年开始。按大规模耕地撂荒发生的起始年份统计, 中国山区县耕地撂荒主要发生在 2000 年以后,尤其 是 2005 年以后 (图 3)。大规模耕地撂荒现象发生 在 2000 年以后的村庄数量 172 个, 占出现撂荒的村 庄总数的 $93.4 \%$,而发生在 2005 年以后的村数量 141 个, 占比 $76.7 \%$, 与劳动力快速析出和劳动力工 资大幅增加的趋势基本吻合, 即撂荒主要发生在 “刘易斯第一转折点”以后。由于在调查过程中,这 一调查项只是村干部估计的一个大概年份, 村干部

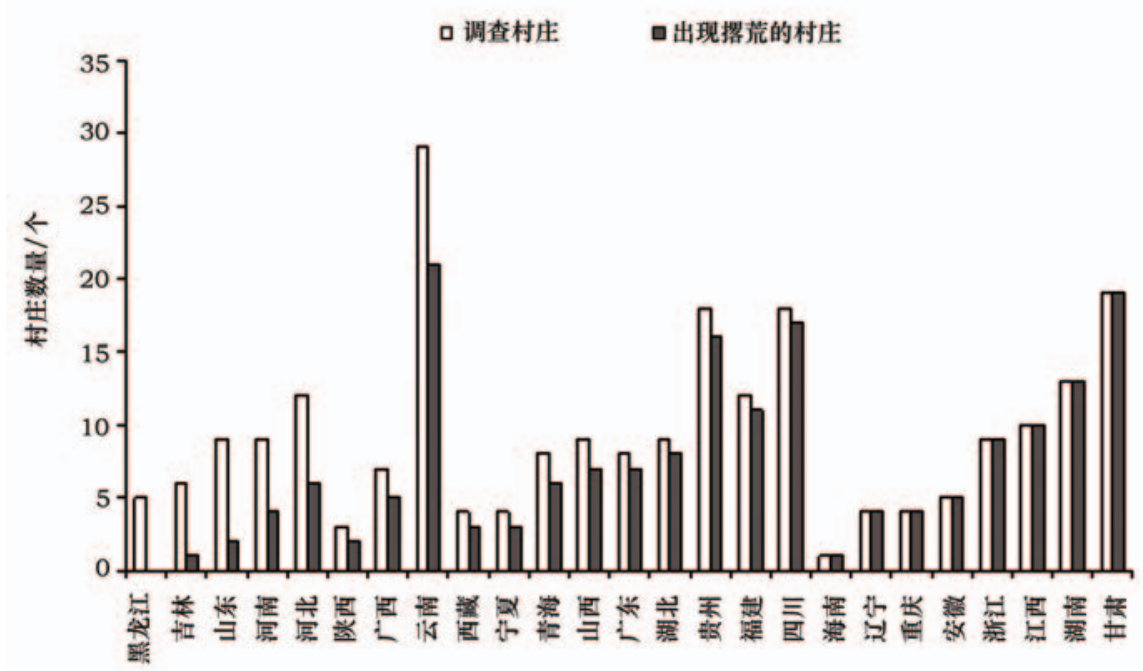

图 2 2014-2015 年中国各省调查村庄和发生撂荒村庄数量

Figure 2 Numbers of investigated villages and villages with cropland abandonment in each province of China from 2014 to 2015

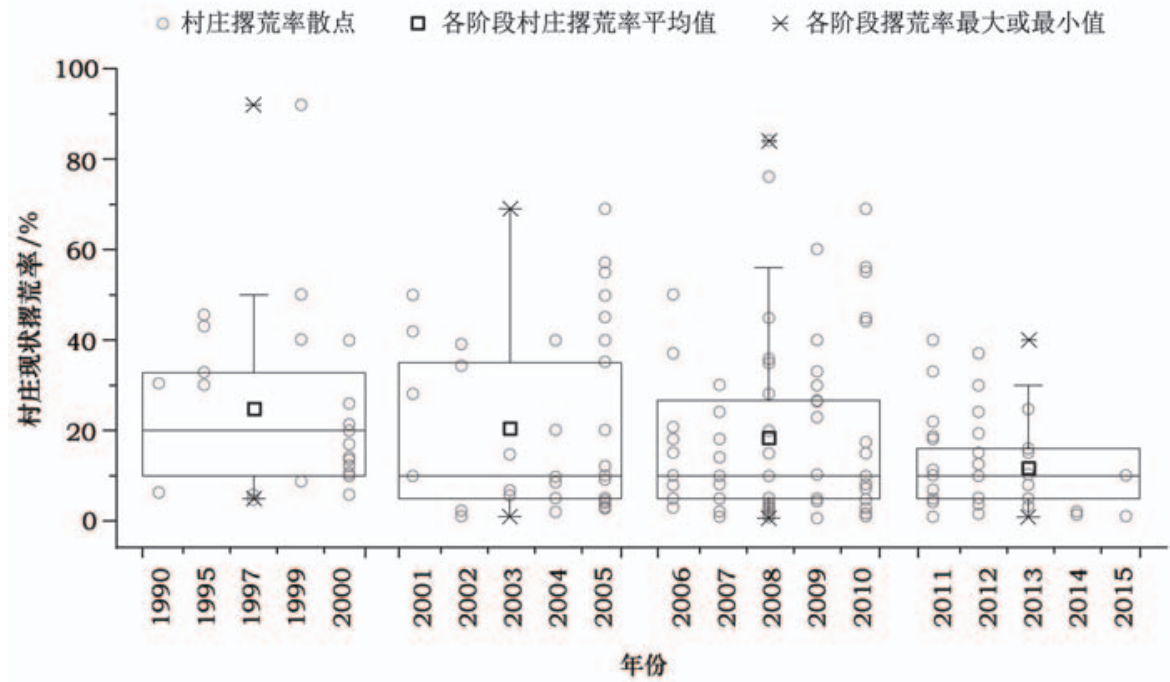

图 3 1990-2015 年中国山区不同撂荒起始阶段的村庄现状撂荒率

Figure 3 The land abandonment rates for different types of villages, categorized by the starting year of land abandonment in mountainous counties in China from 1990 to 2015 
户调查中没有撂荒耕地、但村内有撂荒现象的村庄

更容易将起始年份估计为 2000 年、 2005 年、 2010 年 这些整数年份上。撂荒是一个渐进的过程,理论 上, 撂荒时间发生越早, 耕地边际化程度越深, 因此 撂荒率越高。撂荒发生起始年份的平均撂荒率与 年份的皮尔森相关性达到 $-0.41(P=0.063)$, 而且 2000 年以前、2001-2005年、2006-2010年、2011-2015 年四个阶段的村庄耕地撂荒率平均值依次递减, 表 明了大规模撂荒发生的时间越早, 撂荒发展程度越 深(图 3)。另外,从 2000 年以来的三个阶段的箱线 图还可以看出, 撂荒发生越早, 村庄耕地撂荒率的 平均值和中位数之间的差距越大, 上下边缘之间的 差距也越来越大。这表明随着时间的推进,不同的 村庄耕地撂荒发展趋势并不是一致的,部分村庄的 撂荒程度随时间增加而明显加深, 而另外一些村庄 的耕地撂荒发展相对缓慢,撂荒率并没有随时间明 显增加。不同村庄撂荒发展状况的差异可能主要 与村庄地形条件、耕地资源禀赋有关。

\section{2 全国山区县耕地撂荒程度}

基于村样本面积加权平均的全国山区县 20142015 年耕地撂荒率 I 为 $13.29 \%$, 耕地撂荒率 II 为 $15.30 \%$, 耕地撂荒率 III 为 $16.55 \%$ 。基于县样本面积 加权平均的全国山区县 2014-2015 年耕地撂荒率 I 为 $14.32 \%$, 耕地撂荒率 II 为 $16.57 \%$, 耕地撂荒率 III 为 $17.91 \%$ 。从农户土地利用调查来看, 不考虑分层 计算(公式(2)-公式(4)), 全部调查农户的耕地撂荒 率 I 为 $7.42 \%$, 耕地撂荒率 II 为 $8.24 \%$, 耕地撂荒率 III 为 $9.05 \%$,均约为基于县样本面积加权平均值的 一半。

基于村调查和农户调查的撂荒率之间存在明 显差异原因在于农户选取有一定的偏差。由于撂 荒农户大多常年在外, 从随机选取角度来看, 调查 到的农户大多是“剩余下来”的农户,这些农户的务 农机会成本较低,更偏向从事农业生产,他们宁愿 将土地改种为林木和果树也不撂荒土地。根据农 户调查调查结果, 所调查的农户绝大部分都有在进 行农业生产,完全转为非农的农户数量仅占全部农 户的 $6.8 \%$ 。从土地流转来看,基于农户调查的耕地 总转人率为 $22.0 \%$, 总转出率为 $7.2 \%$, 转出率仅为 转人率的 $1 / 3$ 。从改种的情况来看,基于农户调查 的耕地改种率 $8.2 \%$,高于村调查的 $6.5 \%$ 。另外,农
数量 36 个。所有的这些调查结果均表明, 从测算撂 荒规模的目的来看, 采取随机抽样选取的农户结构 有偏, 撂荒农户比例偏小, 从而导致基于农户调查 所计算的耕地撂荒率偏低。

\section{3 分省山区县耕地撂荒程度}

分省撂荒率分析时采用的是基于县样本面积 加权平均的撂荒率 $\mathrm{I}$ 。结果显示, 撂荒率最高的是 江西和重庆,2014-2015年的撂荒率分别达到 $34.03 \%$ 、 $32.49 \%$ 。其次是广西、四川、浙江、湖南、甘肃, 撂荒 率在 20\% 30\% 之间。再次为安徽、福建、广东、贵 州、海南和西藏等省份，撂荒率在 10\% 20\%之间。 河北、吉林、辽宁、陕西等北方省份的撂荒率基本在 $3 \%$ 以下。从空间分布上, 撂荒率呈现南高北低的分 布格局, 长江流域一带的山区撂荒率最高, 而东北 地区的撂荒率最低(图4)。

\section{5 调查结果的不确定性因素分析}

\section{1 高估的可能因素}

撂荒是一个反复的、渐进的过程。农户在当下 撂荒耕地也有可能在几年以后选择复耕,尤其是一 些年龄相对较大的农户。因此,本研究在调查表设 计过程中特意设置了一个农户对该撂荒地复耕意 愿的选项。根据农户调查结果, 在现有撂荒的耕地 中,农户表示可能在两年内复耕的比重为 $9.06 \%$,亦 即撂荒率有可能高估了约 1.3 个百分点。

\section{2 低估的可能因素}

造成撂荒低估的可能因素主要包括三个方面:

(1) 习惯亩问题。尽管本研究对习惯亩问题进 行了多方纠正,但由于信息量不多,仍然无法全面 地对所有村的习惯亩系数进行测定。基于粮食单 产估算的习惯亩系数也受到村民故意少报粮食产 量的影响。

(2)抽样误差导致。造成抽样误差的重要原因 是已经搬迁或消失的村庄无法调查。 20 世纪 90 年 代末以来, 中国各地山区或其他生态脆弱陆续各省 开展了高山移民搬迁工程、水库移民搬迁工程、易 地扶贫搬迁工程等移民工程。如在 2005-2015 年期 间, 宁夏的生态移民总量就达了 35 万人, 浙江省 2000 年以来实施的各项移民工程, 累积搬迁山区农 户 8.36 万户,共 28.86 万人。由于搬迁后大多远离 


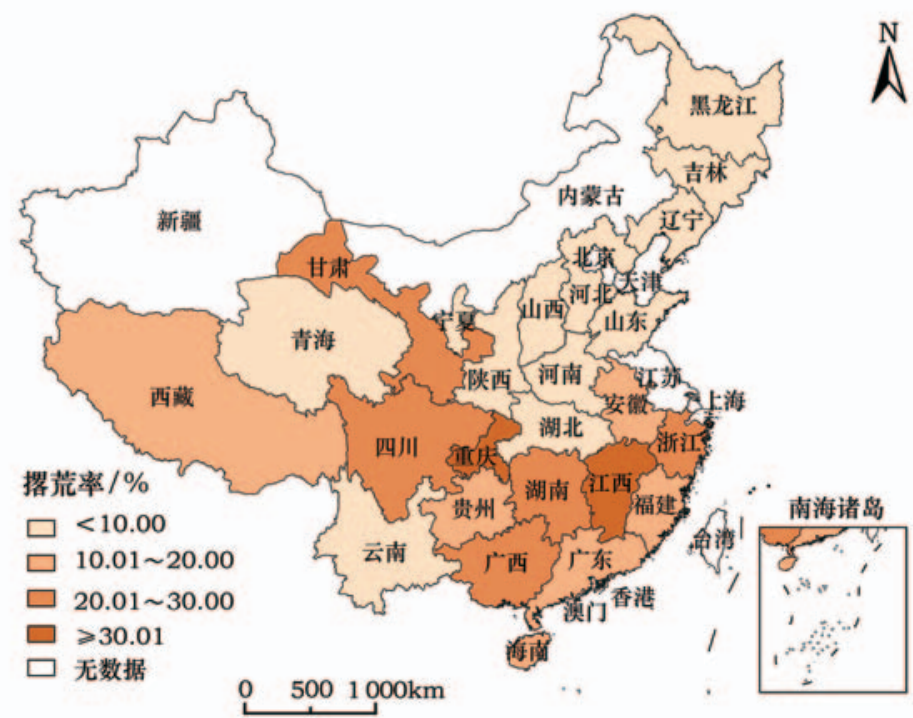

图 4 2014-2015 年中国各省山区县耕地撂荒率

Figure 4 Cropland abandonment rates of mountainous counties at provincial level in China from 2014 to 2015 注: 由于数据获取困难, 本次研究不包括香港、台湾和澳门。

原先的村落,搬迁农民多在迁人地购买土地, 并将 原来耕地撂荒。例如, 在福建实地调查过程中, 有 一个原计划调查的村庄已经基本完成搬迁,全村耕 地全部撂荒。因此,对搬迁村调查的缺失可能会导 致撂荒结果低估,但这一因素无法量化。

(3)人为因素。由于调查结果主要是基于村干 部对本村总体情况的认知,但对于一些负面信息调 查,村干部一般偏保守而瞒报或少报 ${ }^{[28]}$,加之山区行 政村面积广, 自然村数量多,部分村干部对本村的 总体情况了解不足也会导致撂荒率偏低。本研究 已经对部分瞒报的村进行了一定的修正,但对于少 报的情况难以确定,为了避免矫枉过正,本研究并 没有对此进行校正。当然,也有可能出现村干部高 估的可能,但根据调查经验这种情况很少。

\section{3 其他因素}

中国山区范围大, 且各地自然条件、农业发展 水平、社会经济发展状况差异很大,所以尽管调查 农户样本数量较大,并尽量采用了较为合理的抽样 调查方法, 但相对于中国山区范围, 总的样本量仍 偏低, 尤其是部分省份的样本量过少, 如海南, 这也 可能会造成抽样结果的误差增大。因此,对于部分 省份来说, 由于调查样本量少,撂荒率推算的结果 代表性不够。

\section{6 结论}

本文通过大学生假期返乡调查+实地补充调查 相结合的调查方式,基于分层+随机的抽样方法, 对 全国约 900 个山区县进行耕地撂荒抽样调查, 共获 得分布在 25 个省份、142 个山区县的 235 个山区村 和 2994 个农户的耕地撂荒信息。在对习惯亩、调查 误差进行修正的基础上,本文首次定量评估了中国 山区县耕地撂荒发展的总体状况,得出以下研究 结论:

（1）2000年以来,在农业劳动力大量析出、劳动 力价格上升和农业机械化受阻的共同作用下,中国 山区耕地利用边际化特征和现象明显,约 $80 \%$ 调查 村出现耕地撂荒现象,但总体撂荒程度不高,基于 县样本面积加权平均的全国山区县2014-2015 年耕 地撂荒率为 $14.32 \%$ 。

(2) 山区县耕地撂荒率在省级尺度上呈现出南 高北低的总体分布格局,其中,长江流域一带的耕 地撂荒率最高, 华北地区以及东北的长白山区 最低。

(3)耕地撂荒调查受到多个方面因素的综合影 响, 因此调查结果存在一定的不确定性。基于农户 复耕意愿调查,调查结果可能高估了约 1.3 个百分 点。习惯亩问题、抽样误差以及村干部因素等影响 
可能会造成调查结果偏低。

已有研究表明,耕地撂荒对山区农村的社会经 济和生态环境都带来了深刻的影响,如何消除山区 耕地撂荒所带来的负面影响是未来研究的重点。 对中国而言, 尽管总的耕地撂荒程度不高, 但撂荒 发生范围广, 耕地撂荒所带来的社会和生态效应仍 不容忽视。

致谢: 感谢来自 31 个高校参与本次调查的全部 同学。感谢中山大学杜建会老师, 感谢山东师范大 学李子君教授、江西财经大学谢花林教授、河北师 范大学石晓丽老师、湖南师范大学朱红梅教授、福 建师范大学陈松林教授和靳建辉老师、中南民族大 学刘成武教授、西南大学阎建忠教授和李慧莲、广 州大学吴大放老师、海南大学任飞阳等在联系农户 调查员上的帮助。

\section{参考文献(References) :}

[ 1 ] Fang C, Du Y, Wang M. Migration and Labor Mobility in China [R]. New York: United Nations Development Programme, Human Development Report Office, 2009.

[2] 卢锋. 中国农民工工资走势: 1979-2010[J]. 中国社会科学, 2012, (7) : 47-67. [Lu F. Wage trends among Chinese migrant workers: 1979-2010[J]. Social Sciences in China, 2012, (7) : 4767.]

[3] 辛良杰, 李秀涁, 谈明洪, 等. 近年来我国普通劳动者工资变化 及其对农地利用的影响 [J]. 地理研究, 2011, 30 (8): 13911400. [Xin L J, Li X B, Tan M H, et al. The rise of ordinary labor wage and its effect on agricultural land use in present China [J]. Geographical Research, 2011, 30(8): 1391-1400.]

[4] 卢锋, 杨业伟. 中国农业劳动力占比变动因素估测: 1990-2030 年 [J]. 中国人口科学, 2012, (4): 13-24. [Lu F, Yang Y W. Measurement of factors behind the decline of the agricultural labor share in total labor force of China (1990-2030) [J]. Chinese Journal of Population Science, 2012, (4): 13-24.]

[5] 何小勤. 农业劳动力老龄化研究-基于浙江省农村的调查[J]. 人 口与经济, 2013, (2): 69-77. [He X Q. A study on the aging of agriculture labor force: Based on the investigation of Zhejiang Rural Areas[J]. Population \& Economics, 2013, (2): 69-77.]

[6]李澜,李阳. 我国农业劳动力老龄化问题研究-基于全国第二次 农业普查数据的分析 [J]. 农业经济问题, 2009, (6): 61-66. [Li L, Li Y. Analysis and reflection the problem about ageing labor engaged in agricultural production: based on the second national agricultural census statistics in China[J]. Issues in Agricultural Economy, 2009, (6):61-66.]

[7] 蔡昉. 被世界关注的中国农民工-论中国特色的深度城市化 [J]. 国际经济评论, 2010, (2):40-53. [Cai F. China's farmers-turned workers in global spotlight: on deepening of urbanization with Chinese characteristics[J].International Economic Review, 2010, (2): 40-53.]

[8] 陈瑜琦, 李秀涁. 1980 年以来中国耕地利用集约度的结构特征 [J]. 地理学报, 2009, 64 (4): 469-478. [Chen Y, Li X B. Structural change of agricultural land use intensity and its regional disparity in China[J]. Acta Geographica Sinica, 2009, 64 (4) : 469-478.]

[9] 李秀涁, 赵宇变. 森林转型、农地边际化与生态恢复 [J]. 中国人 口・资源与环境, 2011, 21 (10): 91-95. [Li X B, Zhao Y L. Forest transition, agricultural land marginalization and ecological restoration[J]. China Population, Resources and Environment, 2011,21(10):91-95.]

[10] MacDonald D, Crabtree J R, Wiesinger G, et al. Agricultural abandonment in mountain areas of Europe: Environmental consequences and policy response[J]. Journal of Environmental Management, 2000, 59(1): 47-69.

[11] Rudel T K, Coomes O T, Emilio M, et al. Forest transitions: towards a global understanding of land use change[J]. Global Environmental Change, 2005, 15(1):23-31.

[12] Strijker D. Marginal lands in Europe-causes of decline[J]. Basic and Applied Ecology, 2005, 6(2): 99-106.

[13] Estel S, Kuemmerle T, Alcántara C, et al. Mapping cropland abandonment and recultivation across Europe using MODISNDVI time series[J]. Remote Sensing of Environment, 2015, $163: 312-325$.

[14] Xie H, Wang P, Yao G. Exploring the dynamic mechanisms of cropland abandonment based on a spatially explicit economic model for environmental sustainability: a case study in Jiangxi Province, China[J]. Sustainability, 2014, 6(3): 1260-1282.

[15] 定光平, 刘成武, 黄利民. 惠农政策下丘陵山区农地边际化的 理论分析与实证-以湖北省通城县为例 $[\mathrm{J}]$. 地理研究, 2009, 28 (1) : 109-117. [Ding G P, Liu C W, Huang L M. A theoretical analysis and empirical research of marginalization of agricultural land in hilly-mountainous area under farmer-benefiting policy: a case study of Tongcheng County in Hubei Province[J]. Geographical Research, 2009, 28(1): 109-117.]

[16] 邵景安, 张仕超, 李秀涁. 山区耕地边际化特征及其动因与政 策含义[J]. 地理学报, 2014, 69(2): 227-242. [Shao J A, Zhang S C, Li X B. Cropland marginalization in the mountainous areas: characteristics, influencing factors and policy implications[J]. Acta Geographica Sinica, 2014, 69(2): 227-242.] 
[17] 刘成武, 李秀彬. 1980 年以来中国农地利用变化的区域差异 [J]. 地理学报, 2006, 61 (2): 139-145. [Liu C W, Li X B. Regional differences in the changes of the agricultural land use in China during 1980- 2002[J]. Acta Geographica Sinica, 2006, 61(2): 139-145.]

[18] 甘犁, 尹志超, 谭继军. 中国家庭金融调查报告 2014[M]. 成都: 西南财经大学出版社, 2015. [Gan N, Yin Z C, Tan J J. China Household Finance Survey Report 2014[M]. Chengdu: Southwestern University of Finance and Economics Press, 2015.]

[19] Price M F, Butt N. Forests in Sustainable Mountain Development Report for 2000[M]. Wallingford: CAB International, 2000.

[20] 江晓波, 曾鸿程. 量化中国山区范围-以四川省为例[J]. 山地学 报, 2009, 27 (1) : 24-32. [Jiang X B, Zeng H C. Quantifying mountain regions of China-a case study in Sichuan[J]. Journal of Mountain Science, 2009, 27(1):24-32.]

[21] 国家统计局农村社会经济调查司. 中国县域统计年鉴 2012 [M]. 北京: 中国统计出版社, 2014. [Department of Rural Surveys, National Bureau of Statistics of the People's Republic of China. China County Statistical Yearbook 2012[M]. Beijing: China Statistics Press, 2014.]

[22] 谢晨, 彭道黎. 退耕还林政策十年评价-农户的视觉与大学生 的观察 [M]. 北京: 社会科学文献出版社, 2011. [Xie C, Peng D L. Ten Years' Evaluation on the Grain for Green Projecte: Farmers' Vision and College Students' Observation[M]. Beijing: Social Sciences Acadmic Press, 2011.]

[23] 宋伟. 农村住宅功能的区域分异规律研究[J]. 中国农学通报, 2012, 28 (20) : 198-203. [Song W. Research on regional di- fferentiation law of rural house' function[J]. Chinese Agricultural Science Bulletin, 2012, 28(20): 198-203.]

[24] 洪名勇. 农地习俗元制度及其实施机制研究[D]. 南京: 河海大 学, 2007. [Hong M Y. Custom Proto-Institution of Agricultural Land and the Implementation Mechanism[D]. Nanjing: Hohai University, 2007.]

[25] 汪权方, 肖莉,王海滨, 等. 湖北省洪湖市作物播种面积的三种 数据差异分析 [J]. 地理学报, 2008, 63(6): 587-592. [Wang Q F, Xiao L, Wang H B, et al. Difference between statistical data, actual data and prediction data of crop area by using remote sensor imagery in Honghu City, Hubei Province[J]. Acta Geographica Sinica, 2008, 63(6): 587-592.]

[26] 新华网. 重庆耕地计税面积与实际面积相差 1370 万亩 [EB/ OL].(2010-09-10)[2017-08-12]. http://news.qq.com/a/2010091 0/001848.htm. [Xinhuanet. Tax Area of Cropalnd in Chongqing is 13.7 Million Mu Less than the Actual Area[EB/OL]. (2010-0910) [2017-08-12]. http: //news.qq.com/a/20100910/001848.htm.]

[27] 柯刚, 朱道林. 试析“习惯亩”在农村税费改革中的不合理性以贵州六盘水市为例 [J]. 农村经济, 2004, (2): 17-19. [Ke G, Zhu D L. An analysis of the irrationality of "Customary-mu” in rural tax reform: a case study of Liupanshui City in Guizhou[J]. Rural Economy, 2004, (2): 17-19.]

[28] 胡敏, 王成超. 劳动力非农转移对农户耕地撂荒的影响 [J]. 亚 热带资源与环境学报, 2013, 8(2): 56-63. [Hu M, Wang C C Impacts of rural labor's non-agricultural transfer on cropland abandonment[J]. Journal of Subtropical Resources and Environment, 2013, 8(2): 56-63.] 


\title{
Extent and distribution of cropland abandonment in Chinese mountainous areas
}

\author{
LI Shengfa ${ }^{1,2,3}$, LI Xiubin ${ }^{1,2}$, XIN Liangjie ${ }^{1}$, TAN Minghong ${ }^{1}$, WANG Xue ${ }^{1}$, WANG Renjing ${ }^{1,2}$, \\ JIANG Min ${ }^{1,2}$, WANG Yahui ${ }^{1,2}$ \\ (1. Key Laboratory of Land Surface Pattern and Simulation, Institute of Geographical Sciences and Natural Resources Research, \\ Chinese Academy of Sciences, Beijing 100101, China; \\ 2. University of Chinese Academy of Sciences, Beijing 100049, China; \\ 3. Guangzhou Institute of Geography, Guangzhou 510070, China)
}

\begin{abstract}
Cropland abandonment is the main land-use change in mountainous areas globally. It has profoundly altered rural land- use structure, agricultural landscapes, and farmer livelihoods in mountainous areas and has huge environmental and socioeconomic impacts. Since 2000, with the rapid rise in labor costs and the exodus of the rural labor force, croplands in China's mountainous areas have been facing a greater risk of abandonment due to rough terrain and slow development of agricultural mechanization. Case studies and reports have increasingly demonstrated that cropland abandonment in these areas is severe. Considering that sloping croplands account for about $25 \%$ of total croplands in China, cropland abandonment is not only related to informed policy-making regarding land use and sustainable rural development in mountainous areas, but possibly has a significant negative impact on food security. Quantitative analyses of cropland abandonment at a national level in China have not been performed. Hence, in this study, a large-scale survey was carried out to estimate the extent of cropland abandonment in mountainous counties to offer a scientific basis for relevant policy-making and further study of cropland marginalization. The results show that $78.3 \%$ of 235 surveyed villages have experienced cropland abandonment to some extent. During 2014-2015, the abandonment rate of croplands in mountainous counties was $14.32 \%$, showing a distribution pattern of "south-high and north-low" at the provincial level. The abandonment rate for the Yangtze River Basin was the highest, while that for the northeastern mountainous area was the lowest.
\end{abstract}

Key words: cropland marginalization; cropland abandonment; customary- mu; Chinese mountainous areas 